\title{
Social differences in diagnosed depression among adolescents in a Swedish population based cohort
}

\author{
Therese Wirback ${ }^{1 *}$, Jette Möller ${ }^{1}$, Jan-Olov Larsson² and Karin Engström ${ }^{1}$
}

\begin{abstract}
Background: Population based research regarding social differences in diagnosed depression in adolescence is sparse. In this study unique material containing in-and outpatient data was used to determine if low social position in childhood increases the risk of diagnosed depression in adolescence. To further examine this association, gender differences and interactions were explored.

Methods: The study population was extracted from the Stockholm Youth Cohort (SYC), a register based cohort containing psychiatric care for all young people in Stockholm County and information about social position. For the purpose of this study, all in the SYC who turned 13 years old during 2001-2007, in total 169,262 adolescents, were followed up in 2005-2011 for diagnoses of depression until age 18. Associations were estimated with Cox regression models and presented as Hazard Ratios (HR).

Results: The risk of diagnosed depression was higher for adolescents with parents with low education ( $H R=1.1$, $\mathrm{Cl}=1.0-1.2)$ and medium education ( $\mathrm{HR}=1.1, \mathrm{Cl}=1.1-1.2)$ compared to high as well as for those with lower household income (for example, medium low, $\mathrm{HR}=1.2, \mathrm{Cl}=1.1-1.3$ ) and for those with parents who received an unemployment benefit ( $H R=1.3, C l=1.2-1.4)$. No differences were found for those with the lowest household income compared to those with the highest level. Adolescents with parents born outside the Nordic countries had a lower risk of diagnosed depression ( $H R=0.7, \mathrm{Cl}=0.6-0.7)$. An interaction effect was found between gender and parental education.
\end{abstract}

Conclusions: Social differences were found but the magnitude was modest and gender differences small.

Keywords: Socioeconomic status, Cohort study, Depression, Adolescence, Gender

\section{Background}

Depression is a leading cause of years lived with disabilities (YLDs) [1, 2] and often originates early in life [3, 4]. The prevalence of adolescents treated for depression in Sweden has increased during the past two decades, and is more common among females [5]. Much research points at higher risks of poor mental health among adolescents with low social position [e.g. 6-18], though some studies found no association $[19,20]$. There are likely several mechanisms behind social differences, including differential exposure to determinants of depression $[21,22]$ as well as

\footnotetext{
* Correspondence: therese.wirback@ki.se

${ }^{1}$ Department of Public Health Sciences, Karolinska Institutet, Solnavägen 1E,

11365 Stockholm, Sweden

Full list of author information is available at the end of the article
}

negative psychosocial factors which can cluster in persons with low social position. How people describe depressive symptoms and where people seek care can further vary depending on for example academic background [23, 24]. Moreover, children of parents with depression can be at a higher risk for depression [25] both because of social and genetic influence. Overall, the results of studies investigating social differences in depression are hard to summarize due to methodological differences such as the measures used to assess depression as well as social position [7, 9, $11,14,15,17-20,26,27]$. So far most studies on social position and poor mental health in adolescence have been based on psychiatric disorders overall $[14,16,28,29]$, poor mental health overall $[6,8,10,12,13,16,30,31]$, or self-reported depressive symptoms $[7,9,11,15-17,19,26$, 
32]. Only a few studies focus on diagnosed depression or mood disorders specifically [18, 20, 27, 33]. McLaughlin et al. [18] show in their study from the United States that financial hardship in childhood increases the risk of diagnosed mood disorders in adolescence, but low parental education and lower status occupation do not. A Finish study with a focus on late adolescence reports that both low parental income and education increase the risk of depression, but education to a lesser extent [27]. Two less recent studies, one from New Zealand and one from the United States, found no increased risk of depression [20] or mood disorders [33] among groups with low socioeconomic status. Gender-specific risks in relation to social position and mental health problems show inconclusive results [16]. Some studies indicate that girls are more vulnerable $[17,30,34]$ whereas others point to boys' vulnerabilities [10, 31, 32], and some report no gender differences $[6,11,15]$. Only one study looked at gender differences in relation to social position and diagnosed depression [27], and they found merely small differences.

To add to the limited knowledge of social differences in diagnosed depression among adolescents - in a setting where free mental health services are available - this Swedish population based cohort study was performed. It will also increase knowledge on whether boys and girls are equally affected. Registers with several measures of social position and with diagnoses set by professionals within clinical settings was used. The aim was to determine if low social position in childhood increases the risk of diagnosed depression in adolescence (13-17 year olds), and if there are gender-specific differences.

\section{Methods}

\section{Setting and material}

The material derives from Sweden, a country with a relatively strong redistributive system with mental health services for adolescents primarily financed by tax. The public Child and Adolescent Mental Health Service (CAMHS; In Swedish, BUP) is free of charge for the patient. Children and adolescents can be referred to CAMHS from primary care, seek care directly themselves or via their parents. Primary care with public general practitioners, counsellors and therapists, internet-based psychiatric help and psychiatric emergency units (free for children and adolescents) is also available, as well as private therapists (high fee but mainly targeting adults).

This study is based on The Stockholm Youth Cohort (SYC), a register-based cohort containing information of psychiatric care of children and adolescents in Stockholm County Council (SLL) as well as several measures of social position. SYC includes all individuals aged 0-17 residing in Stockholm County at any point in time during 2001 and 2011, ascertained from the Swedish register of the total population [35]. The SYC is built up with linkage to several different health care and administrative registers by the personal identification number for each individual (recoded for research use). The SYC database is held by the Department of Public Health Sciences at Karolinska Institute. The registers used for the current study were: CAMHS, which includes public psychiatric in-and outpatient care in Stockholm County; The Cause of Death Register [36] with dates and causes of death, according to ICD (International Classification of Disease), for Swedish residents; The National Patient Register which initially included all patients treated in psychiatric care and some somatic care at public hospitals, but now includes information about all public in-patient care (from 1984) and out-patient visits to specialized clinics at hospital (from 2001) in Sweden [37], but not primary care; health care registers in SLL (VAL, Swedish acronym) that include inand outpatient care for residents in Stockholm County, including public and private outpatient care clinics and primary care facilities as well as hospitals for public and private inpatient care, financed by SLL but not private specialists [38]; The Longitudinal Integration Database for Health Insurance and Labour Market Studies (LISA, Swedish acronym) [35], with information about employment, education, income and social benefits for those over 16 years old residing in Sweden; The Multi-generation Register which is part of the Total Population Register and includes connections between index persons and their parents [39].

\section{Study population and design}

The study population was extracted from SYC and is defined as adolescents who were residing in Stockholm County the year they turned 13, between 2001 and 2007, i.e. 7 consecutive birth cohorts (born 1988-1994). A total of 169,262 adolescents were followed for 5 years, until they turned 18, in 2005-2011. A closed cohort design was employed. Individuals were censored at whatever occurred first: time of first depression diagnosis, death, moving out of Stockholm County or end of follow up at age of 18. Age was restricted to 18 as individuals in the Swedish health care system are then considered adults and shall seek care at mental health services for adults.

\section{Exposure and outcome Social position}

Parental education and household disposable income was used to assess childhood social position. To capture additional aspects of social position, parental receipt of an unemployment benefit and parental country of origin were assessed. Parents were defined as social parents, i.e. persons that the child lives with, including biological parents, adoptive parents and other adults responsible for the child. Parental education was assessed according 
to the Swedish standard for classification of individual educational programs [40] and was categorized in three groups; low (pre-secondary), medium (upper secondary), and high (post-secondary) based on the parent with the highest education. Household disposable income [35] is an individualized weighted average income, i.e. the sum of the family members' disposable income multiplied by the individual consumption weights and divided by their aggregate consumption weight. It was categorized according to the distribution within the study population in quintiles; low, medium-low, medium, medium-high and high. Receipt of an unemployment benefit was defined and categorised as, two, or the single parent receiving it once or several times, or not. Parental country of birth was categorised into born in Sweden, born in the Nordic countries (but not in Sweden), or born outside the Nordic countries. Adolescents were classified as having non-Swedish parents if the lone or both parents were born outside of Sweden, where the parental country of birth geographically closest to Sweden was used in the categorization. Born in Sweden was the reference category. All measures of social position were assessed at age 12, the year before the start of follow up, and collected from LISA.

\section{Depression}

Depression was defined as a first time depression diagnoses registered at CAMHS or in VAL. Diagnoses are clinical and were not established specifically for the aim of this study. Depression was defined as to include major depressive disorder, unspecified depressive disorder and dysthymic disorder (DSM-IV: 296.20-24, 300.4, 296.30-36, 311 including the DSM-IV based diagnostic code 19 used at CAMHS; ICD-10: F32.0-9, F38.0-8, F39, F33.0-9, F34.8-9).

\section{Confounding and mediation}

Parental depression was considered a potential confounder since previous research have shown that children of parents with depression have a higher risk for depression [25], and a history of depression has been found to confound the relationship between SES (Socioeconomic Status) and major depression among adults [41]. Information regarding parental depression was collected from the National Patient Register and was taken into consideration if it occurred before the child turned 13. Parental depression was defined as occurring if a parent received a diagnosis in in-or outpatient care according to the following diagnoses from ICD 8, 9 and 10; F32.0-9, F33.0-9, F34.1,8,9, F38.0,1,8, F39, 300E, 296B, 311, 300, 296, 301.10, 302.99, 314.99. In the current study $4 \%$ had a mother or father with depression. Measures of social position and psychosocial factors, e.g. childhood adversities such as divorce, which are considered to occur within the causal pathway, were not adjusted for.

\section{Statistical analysis}

The Incidence Rate Ratio (IRR) and corresponding 95\% confidence intervals $(\mathrm{CI})$ of social position and first time onset of diagnosed depression were calculated using Cox regression models and are presented as Hazard Ratios (HR). Boys and girls were analysed jointly as well as separately to explore possible gender differences. Estimates were calculated for all measures of social position separately. Additionally, adjustments were included for parental depression, country of birth, and education. A test for fulfilment of the proportional hazards assumption was performed with a time dependent variable [42]. There was no indication of a violation of the assumption. Additive interactions were calculated by using the Synergy Index (SI) [43, 44]. SI calculations require dichotomized independent variables. For this purpose the following variables were dichotomized: parental education (low/medium vs. high), household income (low/medium low/ medium vs. medium high/high) and parental country of birth (born in Sweden or not). To make use of as much information as possible in the respective analyses, individuals with missing information on respective exposure variable were excluded only for that particular analysis. A sensitivity analysis including complete cases showed no significant differences. All analyses were done using SAS version 9.3 and 9.4 (SAS Institute Inc. Cary, N.C., US.

\section{Results}

Most adolescents had parents with high education level and $9 \%$ had parents with a low level, which corresponds quite well with the national average [45]. Six percent had received an unemployment benefit and 19\% had parents born outside the Nordic countries while 3\% had parents born in Nordic countries. Characteristics of the adolescents are presented in Table 1.

During follow-up, 6439 adolescents, 1978 boys (2.3\%) and 4461 girls (5.4\%), were diagnosed with first time depression. The majority of the cases of depression were identified in the outpatient clinics. Of the adolescents with depression, 242 (3.7\%) had been treated in in-patient care $(0.14 \%$ of the total study population); 84 boys (4.2\% of the depressed boys) and 158 girls (3.5\% of the depressed girls). The mean age for diagnosis of first time depression was 15.36 for girls and 15.38 for boys. Depression was more common in later adolescence, especially for girls. The largest proportion received a diagnosis at the age of $17(27 \%)$ and the smallest at age 13 (12\%). Most adolescents with depression were 
Table 1 Characteristics among the adolescents, with and without diagnosed depression, and by gender

\begin{tabular}{|c|c|c|c|c|c|c|}
\hline & \multicolumn{2}{|c|}{ All $(n=169,262)$} & \multicolumn{2}{|c|}{ Boys $(n=86,888) 51.3 \%$} & \multicolumn{2}{|c|}{ Girls $(n=82,374) 48.7 \%$} \\
\hline & $\begin{array}{l}\text { Depression } \\
(n=6439)\end{array}$ & $\begin{array}{l}\text { No depression } \\
(n=162,823)\end{array}$ & $\begin{array}{l}\text { Depression } \\
(n=1978)\end{array}$ & $\begin{array}{l}\text { No depression } \\
(n=84,910)\end{array}$ & $\begin{array}{l}\text { Depression } \\
(n=4461)\end{array}$ & $\begin{array}{l}\text { No depression } \\
(n=77,913)\end{array}$ \\
\hline & \multicolumn{2}{|l|}{$\%$} & \multicolumn{2}{|l|}{$\%$} & \multicolumn{2}{|l|}{$\%$} \\
\hline \multicolumn{7}{|c|}{ Parental country of origin } \\
\hline Sweden & 67.2 & 63.4 & 66.6 & 63.2 & 67.4 & 63.6 \\
\hline Nordic & 3.3 & 2.9 & 2.8 & 3.0 & 3.5 & 2.8 \\
\hline Outside Nordic & 13.2 & 19.7 & 14.7 & 19.7 & 12.6 & 19.7 \\
\hline Missing & 16.3 & 14.1 & 15.9 & 14.2 & 16.5 & 14.0 \\
\hline \multicolumn{7}{|l|}{ Parental education } \\
\hline High & 44.9 & 47.7 & 46.3 & 47.8 & 44.3 & 47.6 \\
\hline Medium & 44.2 & 41.0 & 43.4 & 41.0 & 44.5 & 41.0 \\
\hline Low & 9.2 & 9.4 & 8.3 & 9.3 & 9.6 & 9.4 \\
\hline Missing & 1.7 & 2.0 & 2.0 & 2.0 & 1.6 & 2.0 \\
\hline \multicolumn{7}{|c|}{ Disposable household income } \\
\hline High & 16.2 & 18.2 & 15.1 & 18.2 & 16.7 & 18.3 \\
\hline Medium high & 20.2 & 19.7 & 21.2 & 19.7 & 19.7 & 19.7 \\
\hline Medium & 22.5 & 20.0 & 23.8 & 20.0 & 21.9 & 20.0 \\
\hline Medium low & 22.4 & 20.4 & 21.8 & 20.5 & 22.7 & 20.4 \\
\hline Low & 17.5 & 20.4 & 16.7 & 20.4 & 17.8 & 20.5 \\
\hline Missing & 1.3 & 1.3 & 1.3 & 1.3 & 1.2 & 1.3 \\
\hline \multicolumn{7}{|c|}{ Parental receipt of an unemployment benefit } \\
\hline Not received & 86.3 & 86.1 & 85.1 & 86.1 & 86.8 & 86.0 \\
\hline Received & 6.7 & 5.3 & 7.5 & 5.4 & 6.4 & 5.3 \\
\hline Missing & 7.0 & 8.6 & 7.4 & 8.6 & 6.8 & 8.7 \\
\hline
\end{tabular}

diagnosed with the CHAMS code 19 (69.4\%), followed by major depressive disorder (23.4\%), unspecified depressive disorder (6\%) and dysthymic disorder (1.2\%).

\section{Childhood social position and risk of diagnosed depression in adolescence}

Crude and adjusted HRs are shown in Tables 2 and 3. The risk of depression diagnosis was slightly higher for adolescents with parents of a low and medium education compared to high $(\mathrm{HR}=1.1)$. Increased risks were found for adolescents with medium-low $(H R=1.2)$, medium $(\mathrm{HR}=1.3)$, and medium-high household income $(H R=1.2)$ when compared to those with the highest. No increased risk was found for those with the lowest income compared to high. Having parents who received an unemployment benefit was associated with a higher risk of diagnosed depression $(H R=1.3)$. Adolescents with parents born outside the Nordic countries had a lower risk of diagnosed depression $(H R=0.7)$, whereas those with parents born in the Nordic countries had a marginally increased risk $(\mathrm{HR}=1.1)$ compared to those with Swedish-born parents. The effect estimates remained or decreased marginally when adjusted for parental depression. Results with adjustments for parental depression are therefore only shown in the first model. Overall, the effect estimates increased slightly when adjusting for parental country of origin and education.

\section{Gender differences}

Girls had a more than twofold increased risk of diagnosed depression compared to boys $(\mathrm{HR}=2.4, \mathrm{CI}=2.3$ 2.6). Gender stratified associations between social position and diagnosed depression showed minor differences. Risk estimates were slightly higher for boys with a lower household income and parental receipt of an unemployment benefit, and for girls with higher parental education; however with overlapping CIs. See Table 3.

Additive interaction effects of gender and different measures of social position are shown in Table 4. Being a girl and having low educated parents had a synergistic effect of $1.2(\mathrm{CI}=1.0-1.4)$.

\section{Discussion}

The findings from this population based cohort study from Sweden expand upon and handle some methodological shortcomings of previous research. In the current 
Table 2 Crude and adjusted Hazard Ratios (HR) of diagnosed depression in adolescence, by social position, $n=169,262$

\begin{tabular}{|c|c|c|c|c|}
\hline Social factors & $\begin{array}{l}\text { Crude } \\
\text { HR }(95 \% \text { Cl) }\end{array}$ & $\begin{array}{l}\text { Adjusted for biological } \\
\text { parents depression } \\
\text { HR }(95 \% \text { Cl) }\end{array}$ & $\begin{array}{l}\text { Adjusted for parental } \\
\text { country of origin } \\
\text { HR }(95 \% \mathrm{Cl})\end{array}$ & $\begin{array}{l}\text { Adjusted for parental country } \\
\text { of origin and education } \\
\text { HR }(95 \% \mathrm{Cl})\end{array}$ \\
\hline \multicolumn{5}{|l|}{ Sex } \\
\hline Boy & 1.0 & & & \\
\hline Girl & $2.4(2.3-2.6)$ & & & \\
\hline \multicolumn{5}{|c|}{ Parental country of origin } \\
\hline Sweden (ref.) & 1.0 & & & \\
\hline Nordic & $1.1(1.0-1.3)$ & & & \\
\hline Outside Nordic & $0.7(0.6-0.7)$ & & & \\
\hline \multicolumn{5}{|l|}{ Parental education } \\
\hline High (ref.) & 1.0 & 1.0 & 1.0 & \\
\hline Medium & $1.1(1.1-1.2)$ & $1.1(1.1-1.2)$ & $1.2(1.1-1.3)$ & \\
\hline Low & $1.1(1.0-1.2)$ & $1.0(0.9-1.1)$ & $1.2(1.1-1.4)$ & \\
\hline \multicolumn{5}{|c|}{ Disposable Household income } \\
\hline High (ref.) & 1.0 & 1.0 & 1.0 & 1.0 \\
\hline Medium high & $1.2(1.1-1.2)$ & $1.1(1.1-1.2)$ & $1.2(1.1-1.3)$ & $1.2(1.1-1.3)$ \\
\hline Medium & $1.3(1.2-1.4)$ & $1.3(1.2-1.4)$ & $1.3(1.2-1.5)$ & $1.3(1.2-1.4)$ \\
\hline Medium low & $1.2(1.1-1.3)$ & $1.2(1.1-1.3)$ & $1.4(1.2-1.5)$ & $1.3(1.2-1.4)$ \\
\hline Low & $1.0(0.9-1.1)$ & $1.0(0.9-1.1)$ & $1.2(1.0-1.3)$ & $1.1(1.0-1.2)$ \\
\hline \multicolumn{5}{|c|}{ Parental receipt of an unemployment benefit } \\
\hline Not received (ref) & 1.0 & 1.0 & 1.0 & 1.0 \\
\hline Received & $1.3(1.2-1.4)$ & $1.2(1.1-1.4)$ & $1.4(1.3-1.6)$ & $1.4(1.2-1.5)$ \\
\hline
\end{tabular}

study it was shown that $3.8 \%$ of $13-17$ year old adolescents received a diagnosis of depression during a follow-up period of 5 years. The risk of diagnosed depression was higher for adolescents with parents who hold a medium education level, have a lower household income, received an unemployment benefit or were born in the Nordic countries. The social differences were however modest and not found for adolescents with the lowest household income. In addition, adolescents with parents born outside the Nordic countries had a lower risk of diagnosis. No prominent gender differences were found.

The increased risk of diagnosed depression for adolescents with a lower household income or with parents with a lower level of education, found in the current study, is in line with results from recent research from Finland and the US. In comparison however, the current study found smaller differences over all, and no increased risk for those with the very lowest income. The latter contrasts the Finnish study, and an increased risk for those in the group with the lowest income was also found in another Finnish study, where self-reported depressive symptoms were studied [46]. This indicates possible national differences, despite the fact that Finland has a welfare state similar to Sweden. Larger social differences, related to education, have also been noted in another study from Sweden, where self-reports of depressive symptoms were studied [17], which could indicate that groups with low social position seek care to a lower extent. The increased risk of depression for adolescents with parents who received an unemployment benefit are also in line with previous studies [17, 47, 48]. McLaughlin et al. [18] suggests that material deprivation such as financial hardship has a stronger association than relative status, as indicated by education for example, which is supported by the results from the current study as social differences related to low income and receipt of unemployment benefit were more prominent than social differences related to education.

One issue that can explain modest social differences in adolescence, as seen in this study, is the theory of social equalization in adolescence. The theory implies that adolescence is the life period when social differences are expected to be the smallest $[13,49]$. Adolescence is a period when youths interact a lot with friends and thereby start to develop their own social position, whereas the social position of younger children depends more on their parents' social position. Differences in the magnitude of social inequalities between different studies cannot be fully explained by this. The Swedish context, with relatively low social differences overall, in combination with a possible social equalization in 
Table 3 Gender stratified Hazard Ratios (HR) of diagnosed depression in adolescence, by social position, $n=169,262$

\begin{tabular}{|c|c|c|c|c|c|c|}
\hline \multirow[t]{2}{*}{ Social factors } & \multicolumn{2}{|l|}{$\begin{array}{l}\text { Crude } \\
\text { HR }(95 \% \mathrm{Cl})\end{array}$} & \multicolumn{2}{|c|}{$\begin{array}{l}\text { Adjusted for parents country of origin } \\
\text { HR }(95 \% \mathrm{Cl})\end{array}$} & \multicolumn{2}{|c|}{$\begin{array}{l}\text { Adjusted for parents country of origin and education } \\
\text { HR }(95 \% \mathrm{Cl})\end{array}$} \\
\hline & Boys & Girls & Boys & Girls & Boys & Girls \\
\hline \multicolumn{7}{|c|}{ Parental country of origin } \\
\hline Sweden (ref.) & 1.0 & 1.0 & & & & \\
\hline Nordic & $0.9(0.7-1.2)$ & $1.2(1.0-1.4)$ & & & & \\
\hline Outside Nordic & $0.7(0.6-0.8)$ & $0.6(0.6-0.7)$ & & & & \\
\hline \multicolumn{7}{|l|}{ Parental education } \\
\hline High (ref.) & 1.0 & 1.0 & 1.0 & 1.0 & & \\
\hline Medium & $1.1(1.0-1.2)$ & $1.2(1.1-1.2)$ & $1.2(1.0-1.3)$ & $1.2(1.1-1.3)$ & & \\
\hline Low & $0.9(0.8-1.1)$ & $1.1(1.0-1.2)$ & $1.1(0.9-1.3)$ & $1.3(1.2-1.5)$ & & \\
\hline \multicolumn{7}{|c|}{ Disposable household income } \\
\hline High (ref.) & 1.0 & 1.0 & 1.0 & 1.0 & 1.0 & 1.0 \\
\hline Medium high & $1.3(1.1-1.5)$ & $1.1(1.0-1.2)$ & $1.4(1.2-1.6)$ & $1.1(1.0-1.3)$ & $1.4(1.2-1.6)$ & $1.1(1.0-1.2)$ \\
\hline Medium & $1.4(1.2-1.7)$ & $1.2(1.1-1.3)$ & $1.5(1.3-1.8)$ & $1.3(1.1-1.4)$ & $1.5(1.3-1.8)$ & $1.2(1.1-1.3)$ \\
\hline Medium low & $1.3(1.1-1.5)$ & $1.2(1.1-1.3)$ & $1.5(1.2-1.7)$ & $1.3(1.2-1.5)$ & $1.4(1.2-1.6)$ & $1.3(1.1-1.4)$ \\
\hline Low & $1.0(0.9-1.2)$ & $1.0(0.9-1.1)$ & $1.2(1.0-1.4)$ & $1.2(1.0-1.3)$ & $1.1(0.9-1.3)$ & $1.1(1.0-1.2)$ \\
\hline \multicolumn{7}{|c|}{ Parental receipt of an unemployment benefit } \\
\hline Not received (ref) & 1.0 & 1.0 & 1.0 & 1.0 & 1.0 & 1.0 \\
\hline Received & $1.4(1.2-1.7)$ & $1.2(1.1-1.4)$ & $1.5(1.3-1.8)$ & $1.4(1.2-1.6)$ & $1.5(1.2-1.8)$ & $1.3(1.2-1.5)$ \\
\hline
\end{tabular}

adolescence, can however add to the explanation as to why a smaller magnitude of social differences were found in the current study. The widespread, and free access to mental health services can further add to the explanation. In addition, it has been shown that the influence of equalization in adolescence can depend on the specific health outcome as well as the measure used for social position [50, 51].

The protective effect of having parents born outside the Nordic countries contrasts earlier findings from a similar population in Sweden, focusing on self-reported depressive symptoms, where no differences between foreign-born and Swedish-born were detected [17, 52]. This indicates that adolescents with parents born outside the Nordic countries may seek care to a lower extent. A previous Swedish study reports that adolescents with parents born in in middle or low-income countries use psychiatric care to a lesser extent than native-born Swedes [53]. Possible explanations can include problems in accessing mental health services or lower health literacy; both in comparison with those whose parents are born in Sweden and in the Nordic countries since Nordic nations have more similar health systems and traditions. Differences can also be related to how depression is expressed and articulated in different cultures [54]. More work is needed to elucidate social differences in care-seeking for depressive symptoms, especially for foreign-born.

As expected, and in line with previous research, both on self-reported depressive symptoms [12, 17, 55] and diagnosed depression [27, 33], girls had an increased risk compared to boys. That girls suffer more from depression can partly depend on the diagnostic criteria or that expressions of depressive symptoms differ between boys

Table 4 Hazard Ratios (HR) and Synergy Index (SI) between gender and social position in diagnosed depression, $n=169,262$

\begin{tabular}{|c|c|c|c|c|c|}
\hline \multirow[t]{2}{*}{ Social factors } & \multicolumn{2}{|l|}{ Male $(95 \% \mathrm{Cl})$} & \multicolumn{2}{|l|}{ Female $(95 \% \mathrm{Cl})$} & \multirow{2}{*}{$\begin{array}{l}\text { Synergy } \\
\text { Index (SI) } \\
(95 \% \text { CI) }\end{array}$} \\
\hline & $\begin{array}{l}\text { Unexposed to social } \\
\text { factor }\end{array}$ & $\begin{array}{l}\text { Exposed to social } \\
\text { factor }\end{array}$ & $\begin{array}{l}\text { Unexposed to social } \\
\text { factor }\end{array}$ & $\begin{array}{l}\text { Exposed to social } \\
\text { factor }\end{array}$ & \\
\hline $\begin{array}{l}\text { Parental education }{ }^{\mathrm{a}} \\
\text { High vs. low/medium }\end{array}$ & 1.0 & $1.1(1.0-1.2)$ & $2.3(2.0-2.6)$ & $2.7(2.5-3.0)$ & $1.2(1.0-1.4)$ \\
\hline $\begin{array}{l}\text { Disposable household income } \\
\text { High vs. low }\end{array}$ & 1.0 & $1.0(0.9-1.1)$ & $2.3(2.2-2.5)$ & $2.5(2.3-2.7)$ & $1.1(0.9-1.3)$ \\
\hline $\begin{array}{l}\text { Parental receipt of an unemployment benefit } \\
\text { Received vs. not received }\end{array}$ & 1.0 & $1.4(1.2-1.7)$ & $2.3(2.2-2.5)$ & $3.1(2.7-3.5)$ & $1.2(0.9-1.5)$ \\
\hline
\end{tabular}

adjusted for parental country of origin

${ }^{\mathrm{b}}$ Adjusted for parental country of origin and education 
and girls [56]. Boys can for example have succumbed to traditional norms of masculinity and not express their symptoms [57]. Regarding the gender-specific risks in relation to social position, the current study support to some extent the findings from studies that did not detect gender differences [6, 11, 15]. Muntaner [58] mention that different SES indicators can perform inconsistently for men and women, and even though only small gender differences were found in the current study there was some indication of inconsistency depending on the SES indicator. In the current study girls living with low educated parents were found to be somewhat more vulnerable for depression, which parallels the findings from one of the research group's previous studies [17] on depressive symptoms. There are contradictory theoretical models to explain an elevated risk of depression depending on social position, for boys and girls respectively. It has been suggested that low parental education is a more powerful risk factor for depression among boys than girls [59]. Girls may not be affected as much as boys by the added vulnerability of low parental education because they are already so vulnerable to depression. However our results support the theoretical model proposed by Cyranowski et al. [60], which proposes that girls are more vulnerable to depression due to the combination of a more affiliative style in social relations and transition difficulties, which are triggered by negative life events. Further, social position can have different meanings and effects on mental health depending on for example the context and ethnicity [61, 62], which highlights the importance of studies from different countries.

A complex picture of the association between social position and depression is revealed, and it reminds us that the indicators used to define social differences describe different dimensions of social position [63]. Income translates into material and immaterial resources and fluctuates to some extent, whereas education is more stable and relates to, for example, health literacy. These different dimensions are considered to be interconnected, and the cause and effect chain depends on what is being studied [63]. Miech et al. [20] has furthermore concluded that different mental disorders are differently related to social position, which points to the importance of research with measures of specific mental disorders and not overall measures of poor mental health.

There are likely several mechanisms behind the social differences, which are not explored in the current study. There are many different determinants for depression, such as negative social circumstances including low social support and poverty [21, 22], and serious conflict during upbringing [64]. Differential exposure to these determinants can cause inequalities. One additional explanation is that of susceptibility, meaning that some social groups are more vulnerable. Long lasting stress is one factor that can contribute to depression [65] but the same amount of stress can affect people differently. Higher SES groups may have better opportunities for social support and know where to turn for help in handling stress. Furthermore, negative psychosocial factors can cluster in persons with low social position and etiological mechanisms can differ depending on at what age depression is present. For example, juvenile onset depression is more affected by adverse childhood factors than adult onset depression [66].

\section{Strengths and limitations}

The possibility to use register-based material, encompassing a large population-based sample of adolescents with both in- and outpatient data, is a great strength of the current study. Including both in- and outpatient data has been found to be important to calculate reliable rates of mental diseases [67]. Population characteristics and the distribution of care utilities are similar to other big cities of Sweden and thus it is possible to generalize to those, as well as to other populations within a similar context. The cohort design allowed an etiological focus and the clinical assessment of diagnoses within CAMHS offered a naturalistic design. Furthermore the diagnostic procedures at CAMHS are based on professional assessment and not on structured instruments to measure depressive symptoms. The use of register-based material decreased problems with self-reported data such as recall bias. Swedish official registers have overall a high standard and are useful for research purposes [68]. Concerning depression, a validation study in Sweden among adults showed $88 \%$ agreement when depression diagnosis from out-patient care was compared to a clinical diagnosis from court-ordered inpatient evaluations [69].

One important limitation of this study is possible misclassification of the outcome, where some adolescents who fulfil the criteria of depression are classified as not having a depression. This can be due to that adolescents with depression often do not seek care [70], reluctance by care givers to diagnose children [71], as well as the possibility of misdiagnosis. The incidence presented may therefore underestimate the true levels of depression in the population. Potential social differences in care-seeking introduce further bias [9] though the direction of the bias is not clear. Finnish studies $[14,72]$ suggest that children of parents with higher socioeconomic position may have better access to care. Differences in care seeking can also apply to gender and ethnic background, where boys in later adolescence and those with parents from ethnic minorities are less likely to seek care [73]. This would result in an underestimation of the risk for those groups in the current study. On the other hand 
some care in the private sector was not included in the current analyses, and if those with higher social position to a higher extent seek private care this would lead to an overestimation of the results.

Another possible, but less severe, limitation is misclassification of exposure due to the procedures for registering housing. Children can only be registered at one address, thus only one social context is considered for those with alternate living arrangements. Furthermore, in the current study the second parent was excluded if he or she was not a biological/adoptive parent, since information for those was differential due to housing conditions, which in turn can be related to social position. This misclassification is not likely to be large but can classify adolescents to a lower social position than they should be, and thus may lead to an underestimation of the associations.

A history of own major depression has been found to confound the relationship between SES and major depression among adults [41] but parental depression only marginally affected the results in the current study, which is in line with findings from Modin et al. [74]. Other measures of poor parental mental health could have been used as also other mental disorders can have an impact on SES and offspring depression. One additional measure of parents' mental disease, defined as any mental disorder severe enough for in-patient care, was tested in the current study. Including this as a confounder changed the estimates marginally compared to adjusting for depression. Childhood adversities and psychosocial factors were considered mediators in the current study as they are within the causal pathway between social position and depression. Patterson et al. [75] imply for example that adversities in youth increase the risk of depression more than family history of parental mental disease do, and that the adversity is more related to SES.

\section{Implications}

The social differences detected in the current study were modest, and still more work needs to be done to reduce social differences. This is especially important considering that a great number of people are affected by depression, and to a higher extent in groups with lower social position. Disentangling the role of social position in care-seeking can further guide the direction of future research, access to care and mental health promotion.

\section{Conclusion}

Social differences in diagnosed depression were found for adolescents in Sweden. The differences were modest and gender differences negligible.

\section{Acknowledgements}

Special thanks to Fredrik Mattsson at FM Statistikkonsult for his assistance with data management.

\section{Funding}

This study was supported by grants from the Swedish Research Council for Health, Working Life and Welfare (FORTE).

\section{Availability of data and materials}

A special license is required to access data from national registers in Sweden. The data for the current study can therefore not be publicly available. If more information about the dataset is requested the authors are happy to provide this.

\section{Authors' contributions}

TW participated in the design of the study, performed the statistical analyses, interpreted the results and drafted the manuscript. JM participated in the design of the study, interpretation of the results and reviewed the manuscript. J-O L contributed with expertise in psychiatrics and reviewed the manuscript. KE participated in the design of the study, interpretation of the results, supported in drafting the manuscript and reviewed the manuscript. All authors read and approved the final manuscript.

Ethics approval and consent to participate

Stockholm regional ethical review board gave ethical approval (2011/63632). The manuscript does not contain clinical studies or patient data. The anonymized data that was used in this study come from registers and informed consent could therefore not be obtained.

\section{Competing interests}

The authors declare that they have no competing interests.

\section{Publisher's Note}

Springer Nature remains neutral with regard to jurisdictional claims in published maps and institutional affiliations.

\section{Author details}

${ }^{1}$ Department of Public Health Sciences, Karolinska Institutet, Solnavägen $1 \mathrm{E}$, 11365 Stockholm, Sweden. 'Department of Women's and Children's Health, Karolinska Institutet, Tomtebodavägen 18A, 17177 Stockholm, Sweden.

Received: 18 January 2018 Accepted: 23 May 2018

Published online: 03 July 2018

\section{References}

1. Vos T, Flaxman AD, Naghavi M, Lozano R, Michaud C, Ezzati M, Shibuya K, Salomon JA, Abdalla S, Aboyans V, et al. Years lived with disability (YLDs) for 1160 sequelae of 289 diseases and injuries 1990-2010: a systematic analysis for the global burden of disease study 2010. Lancet. 2012;380(9859):2163-96.

2. Gore FM, Bloem PJN, Patton GC. Global burden of disease in young people aged 10-24 years: a systematic analysis. Lancet. 2011;378(9790):486.

3. Fryers T, Brugha T. Childhood determinants of adult psychiatric disorder. Clin Pract Epidemiol : CP \& EMH. 2013;9:1-50.

4. Gilman SE, Kawachi I, Fitzmaurice GM, Buka SL. Socioeconomic status in childhood and the lifetime risk of major depression. Int J Epidemiol. 2002; 31(2):359-67.

5. National Board of Health and Welfare. Public Health Report 2009. Stockholm: National Board of Health and Welfare; 2009

6. Amone-P'Olak K, Burger $\mathrm{H}$, Ormel J, Huisman $\mathrm{M}$, Verhulst $\mathrm{FC}$, Oldehinkel AJ. Socioeconomic position and mental health problems in pre- and earlyadolescents: the TRAllS study. Soc Psychiatry Psychiatr Epidemiol. 2009; 44(3):231-8.

7. Lemstra M, Neudorf C, D'Arcy C, Kunst A, Warren LM, Bennett NR. A systematic review of depressed mood and anxiety by SES in youth aged 10-15 years. Can J Public Health Revue canadienne de sante publique. 2008:99(2):125-9.

8. Rajmil L, Herdman M, Ravens-Sieberer U, Erhart M, Alonso J. Socioeconomic inequalities in mental health and health-related quality of life (HRQOL) in children and adolescents from 11 European countries. Int J Public Health. 2013;59(1):95-105 
9. Goodman E, Huang B. Socioeconomic status, depression, and health service utilization among adolescent women. Women's Health Issues. 2001;11(5): 416-26.

10. Huisman M, Araya R, Lawlor DA, Ormel J, Verhulst FC, Oldehinkel AJ. Cognitive ability, parental socioeconomic position and internalising and externalising problems in adolescence: findings from two European cohort studies. Eur J Epidemiol. 2010;25(8):569-80.

11. Jackson B, Goodman E. Low social status markers: do they predict depressive symptoms in adolescence? Race Soc Probl. 2011;3(2):119-28.

12. Piko B, Fitzpatrick KM. Does class matter? SES and psychosocial health among Hungarian adolescents. Soc Sci Med. 2001;53(6):817-30.

13. Sonego M, Llacer A, Galan I, Simon F. The influence of parental education on child mental health in Spain. Qual Life Res. 2013;22(1):203-11.

14. Paananen R, Ristikari T, Merikukka M, Gissler M. Social determinants of mental health: a Finnish nationwide follow-up study on mental disorders. J Epidemiol Community Health. 2013;67(12):1025-31.

15. Aslund C, Leppert J, Starrin B, Nilsson KW. Subjective social status and shaming experiences in relation to adolescent depression. Arch Pediatr Adolesc Med. 2009;163(1):55-60.

16. Reiss F. Socioeconomic inequalities and mental health problems in children and adolescents: a systematic review. Soc Sci Med. 2013;90(0): 24-31.

17. Wirback T, Moller J, Larsson JO, Galanti MR, Engstrom K. Social factors in childhood and risk of depressive symptoms among adolescents - a longitudinal study in Stockholm, Sweden. Int J Equity Health. 2014;13 https://doi.org/10.1186/s12939-014-0096-0.

18. McLaughlin KA, Breslau J, Green JG, Lakoma MD, Sampson NA, Zaslavsky AM, Kessler RC. Childhood socio-economic status and the onset, persistence, and severity of DSM-IV mental disorders in a US national sample. Soc Sci Med. 2011;73(7):1088-96.

19. Twenge JM, Nolen-Hoeksema S. Age, gender, race, socioeconomic status, and birth cohort differences on the children's depression inventory: a metaanalysis. J Abnorm Psychol. 2002;111(4):578-88.

20. Miech RA, Caspi A, Moffitt TE, Wright BRE, Silva PA. Low socioeconomic status and mental disorders: a longitudinal study of selection and causation during young adulthood. Am J Sociol. 1999;104(4):1096-131.

21. Molarius A, Berglund K, Eriksson C, Eriksson HG, Linden-Bostrom M, Nordstrom E, Persson C, Sahlqvist L, Starrin B, Ydreborg B. Mental health symptoms in relation to socio-economic conditions and lifestyle factors-a population-based study in Sweden. BMC Public Health. 2009;9:302.

22. Ostberg $\mathrm{V}$, Lennartsson $\mathrm{C}$. Getting by with a little help: the importance of various types of social support for health problems. Scand J Public Health 2007;35(2):197-204.

23. Danielsson U. Träffad av blixten eller långsam kvävning: genuskodade uttryck för depression i en primärvårdskontext. Umeå: Umeå university; 2010.

24. Wallerblad A, Moller J, Forsell Y. Care-seeking pattern among persons with depression and anxiety: a population-based study in Sweden. Int J Fam Med. 2012;2012:895425.

25. Beardslee WR, Keller MB, Lavori PW, Staley J, Sacks N. The impact of parental affective disorder on depression in offspring: a longitudinal follow-up in a nonreferred sample. J Am Acad Child Adolesc Psychiatry. 1993;32(4):723-30.

26. Joinson C, Kounali D, Lewis G. Family socioeconomic position in early life and onset of depressive symptoms and depression: a prospective cohort study. Soc Psychiatry Psychiatr Epidemiol. 2017;52(1):95-103.

27. Korhonen K, Remes $\mathrm{H}$, Martikainen P. Education as a social pathway from parental socioeconomic position to depression in late adolescence and early adulthood: a Finnish population-based register study. Soc Psychiatry Psychiatr Epidemiol. 2017;52(1):105-16.

28. Spady DW, Schopflocher DP, Svenson LW, Thompson AH. Prevalence of mental disorders in children living in Alberta, Canada, as determined from physician billing data. Arch Pediatr \& Adolesc Med. 2001;155(10):1153-9.

29. Tonge BJ, Hughes GC, Pullen JM, Beaufoy J, Gold S. Comprehensive description of adolescents admitted to a public psychiatric inpatient unit and their families. Aust N Z J Psychiatry. 2008:42(7):627-35.

30. Leve LD, Kim HK, Pears KC. Childhood temperament and family environment as predictors of internalizing and externalizing trajectories from ages 5 to 17. J Abnorm Child Psychol. 2005;33(5):505-20.

31. Due P, Lynch J, Holstein B, Modvig J. Socioeconomic health inequalities among a nationally representative sample of Danish adolescents: the role of different types of social relations. J Epidemiol Community Health. 2003;57(9): $692-8$.

32. Frojd S, Marttunen M, Pelkonen M, von der Pahlen B, Kaltiala-Heino R. Perceived financial difficulties and maladjustment outcomes in adolescence. Eur J Pub Health. 2006;16(5):542-8.

33. Roberts RE, Roberts CR, Xing Y. Rates of DSM-IV psychiatric disorders among adolescents in a large metropolitan area. J Psychiatr Res. 2007;41(11):959-67.

34. Mendelson T, Kubzansky LD, Datta GD, Buka SL. Relation of female gender and low socioeconomic status to internalizing symptoms among adolescents: a case of double jeopardy? Soc Sci Med. 2008;66(6):1284-96.

35. Statistics Sweden. Background facts, labour and education statistics 2011: 4. Stockholm: Integrated database for labour market research; 2011.

36. The National Board of Health and Welfare. 2016. Available from: http://www. socialstyrelsen.se/register/dodsorsaksregistret [cited 2016 March 8].

37. The National Board of Health and Welfare. 2016. Available from: http://www. socialstyrelsen.se/register/halsodataregister/patientregistret/inenglish [cited 2016 March 8].

38. Stockholm County Council. VAL databaserna - datalager för uppföljning av vårdhändelser i SLL. Stockholm läns landsting: Stockholm; 2014.

39. Statistics Sweden: Background Facts, Population and Welfare Statistics 2011:2, Multi-generation register 2010. A description of contents and quality 2011

40. Statistics Sweden: SUN. Swedish standard for classification of individual educational programs 2000.

41. Wang JL, Schmitz N, Dewa CS. Socioeconomic status and the risk of major depression: the Canadian National Population Health Survey. J Epidemiol Community Health. 2010;64(5):447-52.

42. Paul A. Survival analysis using SAS: a practical guide; second edition [electronic resource]: North Carolina: SAS Institute; 2010.

43. Lundberg M, Fredlund P, Hallqvist J, Diderichsen F. A SAS program calculating three measures of interaction with confidence intervals. Epidemiol. 1996;7(6):655-6.

44. Rothman KJ. In: GS RKJ, Lash TL, editors. Modern epidemiology. 3rd ed. Philadelphia: Lippincott Williams \& Wilkins; 2008

45. Finding statistics. Population statistics http://www.statistikdatabasen.scb.se/ pxweb/sv/ssd/START_UF_UF0506/Utbildning/?rxid=1f210474-5ffe-452db3f9-cd9d0499962f [cited 2017 November 7].

46. Elovainio M, Pulkki-Raback L, Jokela M, Kivimaki M, Hintsanen M, Hintsa T, Viikari J, Raitakari OT, Keltikangas-Jarvinen L. Socioeconomic status and the development of depressive symptoms from childhood to adulthood: a longitudinal analysis across 27 years of follow-up in the young Finns study. Soc Sci Med. 2012;74(6):923-9.

47. Kaltiala-Heino R, Rimpela M, Rantanen P, Laippala P. Adolescent depression: the role of discontinuities in life course and social support. J Affect Disord. 2001;64(2-3):155-66

48. Aslund C, Nilsson KW, Starrin B, Sjoberg RL. Shaming experiences and the association between adolescent depression and psychosocial risk factors. Eur Child Adolesc Psychiatry. 2007;16(5):298-304.

49. West $P$. Health inequalities in the early years: is there equalisation in youth? Soc Sci Med. 1997:44(6):833-58.

50. Chen E, Martin AD, Matthews KA. Socioeconomic status and health: do gradients differ within childhood and adolescence? Soc Sci Med. 2006;62(9): 2161-70.

51. Spencer NJ. Social equalization in youth: evidence from a cross-sectional British survey. Eur J Pub Health. 2006;16(4):368-75.

52. Swedish National Institute of Public Health: Survey of mental health among children and adolescents. Results of the national total population study in grades 6 and 9, autumn 2009. Mölnlycke: Swedish National Institute of Public Health; 2011

53. Ivert AK, Merlo J, Svensson R, Levander MT. How are immigrant background and gender associated with the utilisation of psychiatric care among adolescents? Soc Psychiatry Psychiatr Epidemiol. 2013;48(5):693-9.

54. Niemi ME, Falkenberg T, Nguyen MTT, Nguyen MTN, Patel V, Faxelid E. The social contexts of depression during motherhood: a study of explanatory models in Vietnam. J Affect Disord. 2010:124(1-2):29-37.

55. SBU. Treatment of Depression. A Systematic Review. Stockholm: The Swedish Council on Technology Assessment in Health Care (SBU); 2004.

56. Mackenbach JP. Health inequalities : Europe in profile. London: Produced by COl for the Dept of Health; 2006

57. Wirback T, Forsell Y, Larsson J-O, Engstrom K, Edhborg M. Experiences of depression and help-seeking described by young Swedish men. Psychol Men Masc. Advance online publication 2017. 
58. Muntaner C, Eaton WW, Miech R, O'Campo P. Socioeconomic position and major mental disorders. Epidemiol Rev. 2004;26:53-62.

59. Ritsher JE, Warner V, Johnson JG, Dohrenwend BP. Inter-generational longitudinal study of social class and depression: a test of social causation and social selection models. British J Psychiatry Suppl. 2001;40:584-90.

60. Cyranowski JM, Frank E, Young E, Shear MK. Adolescent onset of the gender difference in lifetime rates of major depression: a theoretical model. Arch Gen Psychiatry. 2000;57(1):21-7.

61. Courtenay WH. Constructions of masculinity and their influence on men's wellbeing: a theory of gender and health. Soc Sci Med. 2000;50(10):1385-401.

62. Ochi M, Fujiwara T, Mizuki R, Kawakami N, Grp WMHJS. Association of socioeconomic status in childhood with major depression and generalized anxiety disorder: results from the world mental health Japan survey 20022006. BMC Public Health. 2014;14 https://doi.org/10.1186/1471-2458-14-359.

63. Geyer S, Hemstrom O, Peter R, Vagero D. Education, income, and occupational class cannot be used interchangeably in social epidemiology. Empirical evidence against a common practice. J Epidemiol Community Health. 2006;60(9):804-10.

64. Fors S, Lennartsson C, Lundberg O. Childhood living conditions, socioeconomic position in adulthood, and cognition in later life: exploring the associations. J Gerontol Ser B Psychol Sci Soc Sci. 2009; 64(6):750-7.

65. Socialstyrelsen. Folkhälsorapport 2009. Stockholm: Socialstyrelsen; 2009.

66. Jaffee SR, Moffitt TE, Caspi A, Fombonne E, Poulton R, Martin J. Differences in early childhood risk factors for juvenile-onset and adult-onset depression. Arch Gen Psychiatry. 2002:59(3):215-22.

67. Jorgensen L, Ahlbom A, Allebeck P, Dalman C. The Stockholm non-affective psychoses study (snaps): the importance of including out-patient data in incidence studies. Acta Psychiatr Scand. 2010;121(5):389-92.

68. Allebeck P. The use of population based registers in psychiatric research. Acta Psychiatr Scand. 2009;120(5):386-91.

69. Fazel S, Wolf A, Chang Z, Larsson H, Goodwin GM, Lichtenstein P. Depression and violence: a Swedish population study. Lancet Psychiat. 2015; 2(3):224-32.

70. Essau CA. Frequency and patterns of mental health services utilization among adolescents with anxiety and depressive disorders. Depressn Anxiety. 2005;22(3):130-7.

71. Wasserman D: Depression-en vanlig sjukdom. Stockholm: Natur och Kultur; 2010

72. Paananen R, Santalahti P, Merikukka M, Ramo A, Wahlbeck K, Gissler M. Socioeconomic and regional aspects in the use of specialized psychiatric care-a Finnish nationwide follow-up study. Eur J Pub Health. 2013;23(3): $372-7$.

73. Zwaanswijk M, Verhaak PF, Bensing JM, van der Ende J, Verhulst FC. Help seeking for emotional and behavioural problems in children and adolescents: a review of recent literature. Eur Child Adolesc Psychiatry. 2003; 12(4):153-61.

74. Modin B, Ostberg V, Almquist Y. Childhood peer status and adult susceptibility to anxiety and depression. A 30-year hospital follow-up. J Abnorm Child Psychol. 2011:39(2):187-99.

75. Patterson V, Mackenzie L, Zwicker A, Drobinin V, Cumby J, Abidi S, Bagnell A, Propper L, Alda M, Uher R. Adversity, parental mental illness, and risk of depression in youth. Eur Psychiat. 2017;41:S220.

\section{Ready to submit your research? Choose BMC and benefit from:}

- fast, convenient online submission

- thorough peer review by experienced researchers in your field

- rapid publication on acceptance

- support for research data, including large and complex data types

- gold Open Access which fosters wider collaboration and increased citations

- maximum visibility for your research: over $100 \mathrm{M}$ website views per year

At BMC, research is always in progress.

Learn more biomedcentral.com/submissions 